\title{
Genetic Loci Associated with Platelet Traits and Platelet Disorders
}

\author{
Natalia Bunimov, $\mathrm{PhD}^{1}$ Nola Fuller, $\mathrm{MSc}^{1}$ Catherine P. M. Hayward, MD, PhD, $\operatorname{FRCP}(C)^{1,2,3}$ \\ ${ }^{1}$ Department of Pathology and Molecular Medicine, McMaster \\ University, Hamilton, Ontario, Canada \\ 2 Department of Medicine, McMaster University, Hamilton, Ontario, \\ Canada

\begin{abstract}
Address for correspondence Catherine P. M. Hayward, MD, PhD, FRCP(C), Department of Pathology and Molecular Medicine, McMaster University, 2N29A, 1280 Main Street, West Hamilton, Ontario, L8S 4K1
\end{abstract} \\ Canada (e-mail: haywrdc@mcmaster.ca).
}

${ }^{3}$ Hamilton Regional Laboratory Medicine Program, Hamilton, Ontario, Canada

Semin Thromb Hemost 2013;39:291-305.

\begin{abstract}
Keywords

- platelet function

- inherited platelet disorders

- genome-wide association studies

- platelet aggregation

- platelet secretion

Genetic investigations have led to important advances in our knowledge of genes, proteins, and microRNA that influence circulating platelet counts, platelet size, and function. The application of genome-wide association studies (GWAS) to platelet traits has identified multiple loci with a significant association to platelet number, size, and function in aggregation and granule secretion assays. Moreover, the genes altered by disease-causing mutations have now been identified for several platelet disorders, including X-linked recessive, autosomal dominant, and autosomal recessive platelet disorders. Some mutations that cause inherited platelet disorders involve genes that GWAS have associated to platelet traits. Although disease-causing mutations in many rare and syndromic causes of platelet disorders have now been characterized, the genetic mutations that cause common inherited platelet disorders, and impair platelet aggregation and granule secretion, are largely unknown. This review summarizes current knowledge on the genetic loci that influence platelet traits, including the genes with well-characterized mutations in certain inherited platelet disorders.
\end{abstract}

Platelets play an important role in hemostasis and their function traits are emerging to have important genetic influences. Platelet function is complex: with vascular injury, normal platelets adhere to exposed collagen and to von Willebrand factor bound to collagen. ${ }^{1-3}$ This triggers the generation and secretion of thromboxane $\mathrm{A}_{2}\left(\mathrm{TXA}_{2}\right)$ and platelet storage granule release. ${ }^{1-3}$ Platelets then undergo further activation, with intracellular signaling triggered by their released TXA , adenosine diphosphate (ADP), serotonin, and other agonists (such as thrombin) that are generated at the sites of vessel injury. ${ }^{1-3}$ Genetic defects can impair platelet hemostatic function in many ways, from modifying platelet-vessel wall interactions, through changes in the number of circulating platelets, and/or their size, adhesive properties, responses to agonists, intracellular signaling, granule release, and the feedback that signaling and secretion have on platelet activation and prohemostatic function. ${ }^{1-3}$

published online March 6, 2013
Issue Theme Quality in Hemostasis and Thrombosis, Part II; Guest Editors, Giuseppe Lippi, MD, Mario Plebani, MD, and Emmanuel J. Favaloro, PhD, FFSC (RCPA).
The purpose of this review is to summarize the current state of knowledge on the genetic loci that influence platelet functions and traits, including the genes that may contain disease-causing mutations in those characterized forms of inherited platelet disorders and other conditions that modify platelets.

\section{Inheritance of Platelet Traits and Platelet Disorders}

Megakaryocytes transcribe a huge number of genes, and platelets are estimated to contain more than 1,000 proteins. ${ }^{4-11}$ Twin studies have provided evidence that platelet traits and function are influenced by genetic factors. ${ }^{12}$ Studies of families and candidate genes have led to the identification of several genetic loci that are strongly associated with platelet physiologic and pathologic function. ${ }^{13-29}$ Genome-wide
Copyright $\odot 2013$ by Thieme Medical Publishers, Inc., 333 Seventh Avenue, New York, NY 10001, USA. Tel: +1(212) 584-4662.
DOI http://dx.doi.org/ $10.1055 / \mathrm{s}-0033-1334466$. ISSN 0094-6176. 
292 Genetic Loci Associated with Platelet Traits and Disorders Bunimov et al.

Table 1 Human single nucleotide polymorphisms that have been associated with platelet count, volume, and function as measured by light-transmission platelet aggregation or secretion assays ${ }^{\mathrm{a}}$

\begin{tabular}{|c|c|c|c|c|c|c|}
\hline Trait & Gene & Protein & Population & $\begin{array}{l}\text { SNP with lowest } \\
p \text { value for locus } \\
\text { (associated trait) }\end{array}$ & Cytoband & Reference \\
\hline Count & HSPB7 & $\begin{array}{l}\text { Heat shock } 27 \mathrm{kDa} \text { protein } \\
\text { family, member } 7\end{array}$ & $A U, D$ & rs1763611 & $1 \mathrm{p} 36.23$ & 14 \\
\hline MPV & LAPTM4A, SDC1 & $\begin{array}{l}\text { Lysosomal-associated trans- } \\
\text { membrane protein } 4 \mathrm{~A} \text {, syn- } \\
\text { decan-1 }\end{array}$ & $\mathrm{E}$ & rs11686303 & $2 \mathrm{p} 24.1$ & 15 \\
\hline Count & KCNJ3 & $\begin{array}{l}\text { G protein-activated inward } \\
\text { rectifier potassium channel } 1\end{array}$ & $A U, D$ & rs11682195 & $2 q 24.1$ & 14 \\
\hline $\begin{array}{l}\text { Collagen-induced } \\
\text { secretion }\end{array}$ & MAGI1 & $\begin{array}{l}\text { Membrane-associated gua- } \\
\text { nylate kinase, WW and PDZ } \\
\text { domain containing protein } 1\end{array}$ & SA & rs1318477 & $3 p 14.1$ & 16 \\
\hline \multirow[t]{2}{*}{ Count, MPV } & \multirow[t]{2}{*}{ ARHGEF3 } & \multirow{2}{*}{$\begin{array}{l}\text { Rho guanine nucleotide } \\
\text { exchange factor } 3\end{array}$} & $A U, D$ & rs1354034 (count) & \multirow[t]{2}{*}{$3 p 14.3$} & \multirow[t]{2}{*}{14,15} \\
\hline & & & $\mathrm{E}$ & rs12485738 (MPV) & & \\
\hline $\begin{array}{l}\text { Aggregation with } \\
\text { collagen/ } \\
\text { thromboxane }\end{array}$ & MME & Neprilysin & $E$ & rs1436634 & $3 q 25.2$ & 17 \\
\hline Count & THPO & Thrombopoietin & J & rs6141 & $3 q 27.1$ & 18 \\
\hline Count & KCNIP4 & $\begin{array}{l}\text { Kv channel-interacting } \\
\text { protein } 4\end{array}$ & $A U, D$ & rs13150985 & $4 p 15.32$ & 14 \\
\hline MPV & UNC5C & Netrin receptor UNC5C & $\mathrm{E}$ & rs265013 & $4 q 22.3$ & 15 \\
\hline Count & $\mathrm{CDH} 10$ & Cadherin-10 & $A U, D$ & rs10043237 & $5 p 14.2$ & 14 \\
\hline Count & BAK1 & $\begin{array}{l}\text { Bcl-2 homologous antago- } \\
\text { nist/killer }\end{array}$ & J & rs5745568 & $6 p 21.31$ & 18 \\
\hline Count & PHACTR1 & $\begin{array}{l}\text { Phosphatase and actin } \\
\text { regulator }\end{array}$ & $A U, D$ & rs12212807 & $6 p 24.1$ & 14 \\
\hline Count & GMDS & $\begin{array}{l}\text { GDP-mannose 4,6 } \\
\text { dehydratase }\end{array}$ & SA & rs4463305 & $6 p 25.3$ & 16 \\
\hline \multirow[t]{2}{*}{ Count } & \multirow[t]{2}{*}{$H B S 1 L, M Y B$} & \multirow{2}{*}{$\begin{array}{l}\text { HBS1-like protein, transcrip- } \\
\text { tional activator Myb }\end{array}$} & $A U, D$ & rs9399137 & \multirow[t]{2}{*}{$6 q 23.3$} & \multirow[t]{2}{*}{14,18} \\
\hline & & & $J$ & rs7775698 & & \\
\hline $\begin{array}{l}\text { Aggregation with } \\
\text { collagen/ } \\
\text { thromboxane }\end{array}$ & IPCEF1 & $\begin{array}{l}\text { Interactor protein for cyto- } \\
\text { hesin exchange factors } 1\end{array}$ & $\mathrm{E}$ & rs1534446 & $6 q 25.2$ & 17 \\
\hline MPV & PIK3CG & $\begin{array}{l}\text { Phosphoinositol-4,5-biphos- } \\
\text { phaste 3-kinase (g subunit) }\end{array}$ & $E$ & rs342293 & $7 q 22.3$ & 19 \\
\hline $\begin{array}{l}\text { Aggregation with } \\
\text { ristocetin }\end{array}$ & C8orf86 & $\begin{array}{l}\text { Uncharacterized protein } \\
\text { C8orf86 }\end{array}$ & SA & rs7845393 & $8 p 11.22$ & 16 \\
\hline $\begin{array}{l}\text { Aggregation with } \\
\text { ristocetin }\end{array}$ & FGFR1 & $\begin{array}{l}\text { Fibroblast growth factor re- } \\
\text { ceptor } 1\end{array}$ & SA & rs7845393 & $8 p 11.22$ & 16 \\
\hline MPV & C8orf22 & $\begin{array}{l}\text { Chromosome } 8 \text { open read- } \\
\text { ing frame } 22\end{array}$ & $\mathrm{E}$ & rs12056729 & $8 q 11.21$ & 15 \\
\hline MPV & CPQ, TSPYL5 & $\begin{array}{l}\text { Carboxypeptidase Q, testis- } \\
\text { specific Y-encoded-like pro- } \\
\text { tein } 5\end{array}$ & $\mathrm{E}$ & rs1835742 & $8 q 22.1$ & 15 \\
\hline $\begin{array}{l}\text { Aggregation with } \\
\text { collagen/ } \\
\text { thromboxane }\end{array}$ & GLIS3 & Zinc finger protein GLIS3 & $E$ & rs10116901 & $9 \mathrm{p} 24.2$ & 17 \\
\hline Count & RCL1 & $\begin{array}{l}\text { RNA 3'-terminal phosphate } \\
\text { cyclase-like protein }\end{array}$ & $E$ & rs385893 & $9 q 24.1$ & 18 \\
\hline Count & $A B C A 1$ & $\begin{array}{l}\text { ATP-binding cassette sub- } \\
\text { family A member } 1\end{array}$ & $A U, D$ & rs11999261 & $9 q 31.1$ & 14 \\
\hline $\begin{array}{l}\text { Aggregation with } \\
A A\end{array}$ & LPAR1 & $\begin{array}{l}\text { Lysophosphatidic acid re- } \\
\text { ceptor } 1\end{array}$ & SA & rs4366150 & $9 q 31.3$ & 16 \\
\hline $\begin{array}{l}\text { Aggregation with } \\
\text { ristocetin }\end{array}$ & CACNB2 & $\begin{array}{l}\text { Voltage-dependent L-type } \\
\text { calcium channel subunit } \beta \text {-2 }\end{array}$ & SA & rs6415964 & 10p12.33 & 16 \\
\hline
\end{tabular}


Table 1 (Continued)

\begin{tabular}{|c|c|c|c|c|c|c|}
\hline Trait & Gene & Protein & Population & $\begin{array}{l}\text { SNP with lowest } \\
p \text { value for locus } \\
\text { (associated trait) }\end{array}$ & Cytoband & Reference \\
\hline $\begin{array}{l}\text { Aggregation with } \\
\text { ristocetin }\end{array}$ & SLC39A12 & Zinc transporter ZIP12 & SA & rs6415964 & 10p12.33 & 16 \\
\hline MPV & PFKP & $\begin{array}{l}\text { Platelet } \\
\text { phosphofructokinase }\end{array}$ & $\mathrm{E}$ & rs1574318 & $10 \mathrm{p} 15.2$ & 15 \\
\hline $\begin{array}{l}\text { Aggregation with } \\
\text { ADP }\end{array}$ & LDHAL6A & $\begin{array}{l}\text { L-lactate dehydrogenase } \\
\text { A-like } 6 \mathrm{~A}\end{array}$ & $\mathrm{AA}$ & rs11024665 & $11 \mathrm{p} 15.1$ & 17 \\
\hline $\begin{array}{l}\text { Aggregation (col- } \\
\text { lagen-induced) }\end{array}$ & MIR100HG & $\begin{array}{l}\text { mir-100-let-7a-2 cluster host } \\
\text { gene }\end{array}$ & $\mathrm{F}$ & rs565229 & $11 q 24.1$ & 20 \\
\hline Count & NFE2, COPZ1 & $\begin{array}{l}\text { Transcription factor NF-E2 } 45 \\
\text { kDa subunit, coatomer } \\
\text { subunit zeta- } 1\end{array}$ & $\mathrm{E}$ & rs10876550 & $12 q 13.13$ & 21 \\
\hline $\begin{array}{l}\text { Aggregation with } \\
\text { ADP }\end{array}$ & ANKS1B & $\begin{array}{l}\text { Ankyrin repeat and sterile } \alpha \\
\text { motif domain-containing } \\
\text { protein } 1 \mathrm{~B}\end{array}$ & $\mathrm{AA}$ & rs17029861 & $12 q 23.1$ & 17 \\
\hline Count & $\mathrm{SH} 2 \mathrm{B3}$ & SH2B adapter protein 3 & J & rs739496 & $12 q 24.21$ & 18 \\
\hline Count, MPV & WDR66 & $\begin{array}{l}\text { WD repeat-containing } \\
\text { protein } 66\end{array}$ & $\mathrm{E}$ & $\begin{array}{l}\text { rs7961894 (count, } \\
\text { MPV) }\end{array}$ & $12 q 24.31$ & 15 \\
\hline $\begin{array}{l}\text { Aggregation with } \\
A A\end{array}$ & $R P P 25$ & $\begin{array}{l}\text { Ribonuclease P protein } \\
\text { subunit p25 }\end{array}$ & SA & rs1867153 & $15 q 24.2$ & 16 \\
\hline \multirow[t]{2}{*}{$\begin{array}{l}\text { Count, aggrega- } \\
\text { tion with AA }\end{array}$} & \multirow[t]{2}{*}{ SCAMP5 } & \multirow[t]{2}{*}{$\begin{array}{l}\text { Secretory carrier-associated } \\
\text { membrane protein } 5\end{array}$} & SA & $\begin{array}{l}\text { rs1867153 } \\
\text { (aggregation) }\end{array}$ & \multirow[t]{2}{*}{$15 q 24.2$} & \multirow[t]{2}{*}{14,16} \\
\hline & & & $A U, D$ & rs2289583 (count) & & \\
\hline Count & GPIBA & Glycoprotein Ib $\alpha$ & J & rs6065 & 17pter-p12 & 18 \\
\hline Count, MPV & TAOK1 & $\begin{array}{l}\text { Serine/threonine-protein } \\
\text { kinase TAO1 }\end{array}$ & $\mathrm{E}$ & rs2138852 & $17 q 11.2$ & 15 \\
\hline Count, MPV & TPM4 & Tropomyosin 4 & $\mathrm{E}, \mathrm{AA}$ & rs8109288 & 19p13.12 & 21 \\
\hline
\end{tabular}

Abbreviations: AA, African American; AU, Australian; D, Dutch; E, European; F, Framingham Heart Study population; J, Japanese; MPV, mean platelet volume; SA, South American.

${ }^{a}$ The chromosome positions and gene(s) closest to the single nucleotide polymorphism are shown, along with the respective proteins encoded by the genes. All associations shown were reported have a $p$ value $\leq 1 \times 10^{-5}$

association studies (GWAS) of different populations have expanded the list of genetic loci that show significant associations to platelet traits ( $\mathbf{-}$ Table 1 summarizes information on the associations with $p$ values $\left.\leq 1 \times 10^{-5}\right) \cdot{ }^{14-25}$ Although there are uncertainties about the degree to which these loci predict normal or pathological platelet variability, the heritability of platelet traits, including platelet "reactivity" to agonists in function tests, offers an attractive explanation for the significant correlation of platelet responses to different agonists in clinical aggregation and secretion assays, for individuals with and without bleeding problems. ${ }^{30-34}$

Among the heritable markers associated with platelet traits, some show associations with size, count, and/or function, and some are associated with more than one platelet trait. Some associations do not clearly map to a single gene and/or show an association to multiple loci (see - Table $\mathbf{1}$ ). Some single nucleotide polymorphisms (SNPs) have been associated with a platelet characteristic in multiple populations, consistent with an influence upon different genetic backgrounds ${ }^{14-16,18,35}$ (see - Table 1). Meta-analyses, which increase the power for detecting associations, have found additional associations for platelet traits ( - Table 2 summarizes data for associations with $p$ values $\leq 1 \times 10^{-5}$ ).
GWAS have associated some noncoding regions of the genome with platelet traits, which indirectly suggests that transcriptional or posttranscriptional regulatory mechanisms are involved in regulating platelet function. ${ }^{36}$ Given that both platelets and megakaryocytes contain unique regulatory microRNA (miRNA), ${ }^{29}$ some GWAS have explored if the genes encoding these short RNA sequences are associated with platelet function traits. ${ }^{16}$ Although strong associations of platelet traits with genes encoding miRNA have not been established by GWAS, this possibility needs to be tested with larger numbers of subjects.

At present, there is small but important overlap between genetic loci that are mutated in platelet disorders ( - Table 3 ) and those that are known to influence platelet traits ( - Tables 1 and 2). Among the genes that show associations to platelet traits by GWAS (-Tables $\mathbf{1}$ and $\mathbf{2}$ ) ${ }^{13-32,36}$ but are not yet implicated as causing platelet function disorders, a number have known or implicated importance to platelet function, production, or other traits, including the genes for the following: thrombopoietin, ${ }^{37}$ the g subunit of phosphoinositol-4,5biphosphate 3 -kinase, ${ }^{38}$ the $\alpha$-2A adrenergic receptor, ${ }^{39}$ platelet endothelial aggregation receptor $1,{ }^{40}$ dynamin $3,{ }^{41}$ multidrug resistance protein $4,{ }^{42}$ tropomyosin $4,{ }^{43}$ proteinase- 
294 Genetic Loci Associated with Platelet Traits and Disorders Bunimov et al.

Table 2 Human single nucleotide polymorphisms that have been associated with platelet function through meta-analysis of genome-wide association studies ${ }^{\mathrm{a}}$

\begin{tabular}{|c|c|c|c|c|c|c|}
\hline Trait & Gene & Protein & Population & $\begin{array}{l}\text { SNP with lowest } \\
p \text { value for locus } \\
\text { (associated trait) }\end{array}$ & Cytoband & Reference \\
\hline MPV & KIF1B & Kinesin-like protein KIF1B & $\mathrm{E}$ & rs17396340 & $1 \mathrm{p} 36.22$ & 22 \\
\hline Count & MFN2 & Mitofusin-2 & $\bar{E}$ & rs2336384 & $1 \mathrm{p} 36.22$ & 22 \\
\hline \multirow{2}{*}{$\begin{array}{l}\text { ADP and epi- } \\
\text { nephrine } \\
\text { aggregation }\end{array}$} & \multirow[t]{2}{*}{ PEAR1 } & \multirow[t]{2}{*}{$\begin{array}{l}\text { Platelet endothelial aggregation } \\
\text { receptor } 1\end{array}$} & $\mathrm{E}$ & $\begin{array}{l}\text { rs12566888 } \\
\text { (epinephrine) }\end{array}$ & \multirow[t]{2}{*}{$1 \mathrm{q} 23.1$} & \multirow[t]{2}{*}{25} \\
\hline & & & AA & rs12041331 (ADP) & & \\
\hline Count, MPV & DNM3 & Dynamin 3 & $\mathrm{E}$ & rs10914144 & $1 \mathrm{q} 24.3$ & 22,23 \\
\hline Count, MPV & TMCC2 & $\begin{array}{l}\text { Transmembrane and coiled-coil } \\
\text { domains protein } 2\end{array}$ & E & $\begin{array}{l}\text { rs1668871 (count), } \\
\text { rs1172130 (MPV) }\end{array}$ & $1 \mathrm{q} 32.1$ & 22,23 \\
\hline Count & LOC148824 & $\begin{array}{l}\text { Uncharacterized miscellaneous } \\
\text { RNA gene }\end{array}$ & E & rs7550918 & $1 \mathrm{q} 44$ & 22 \\
\hline Count & TRIM58 & Tripartite motif-containing protein 58 & E & rs3811444 & $1 \mathrm{q} 44$ & 22 \\
\hline Count & THADA & $\begin{array}{l}\text { Thyroid adenoma-associated } \\
\text { protein }\end{array}$ & $E$ & rs17030845 & $2 \mathrm{p} 21$ & 22 \\
\hline Count, MPV & EHD3 & EH domain-containing protein 3 & E & $\begin{array}{l}\text { rs649729 (MPV), } \\
\text { rs625132 (count) }\end{array}$ & $2 \mathrm{p} 21$ & 22,23 \\
\hline Count & GCKR & Glucokinase regulatory protein & E & rs1260326 & $2 p 23$ & 22 \\
\hline MPV & ANKMY1 & $\begin{array}{l}\text { Ankyrin repeat and MYND domain- } \\
\text { containing protein } 1\end{array}$ & $\mathrm{E}$ & rs4305276 & $2 \mathrm{q} 37.3$ & 22 \\
\hline Count, MPV & ARHGEF3 & $\begin{array}{l}\text { Rho guanine nucleotide exchange } \\
\text { factor } 3\end{array}$ & E & $\begin{array}{l}\text { rs1354034 (count), } \\
\text { rs12485738 (MPV) }\end{array}$ & $3 p 14.3$ & 22,23 \\
\hline Count & SATB1 & DNA-binding protein SATB1 & E & rs7641175 & $3 p 23$ & 22 \\
\hline Count & SYN2 & Synapsin-2 & E & rs7616006 & $3 p 25$ & 22 \\
\hline Count & PDIA5 & Protein disulfide-isomerase A5 & $\mathrm{E}$ & rs3792366 & $3 q 21.1$ & 22 \\
\hline MPV & KALRN & Kalirin & $\mathrm{E}$ & rs10512627 & $3 q 21.1$ & 22 \\
\hline Count & THPO & Thrombopoietin & $\mathrm{E}$ & rs6141 & $3 q 27.1$ & 22 \\
\hline MPV & KIAA0232 & Uncharacterized protein KIAA0232 & E & rs11734132 & $4 p 16.1$ & 22 \\
\hline Count & HSD17B13 & $\begin{array}{l}\text { 17- } \beta \text {-hydroxysteroid } \\
\text { dehydrogenase } 13\end{array}$ & E & rs7694379 & $4 q 22.1$ & 22 \\
\hline Count, MPV & $F 2 R$ & Proteinase-activated receptor 1 & E & $\begin{array}{l}\text { rs2227831 (MPV), } \\
\text { rs17568628 (count) }\end{array}$ & $5 q 13.3$ & 22 \\
\hline Count, MPV & MEF2C & $\begin{array}{l}\text { Myocyte-specific enhancer factor } \\
2 \mathrm{C}\end{array}$ & E & rs700585 & $5 q 14.3$ & 22 \\
\hline Count & IRF1 & Interferon regulatory factor 1 & $\mathrm{E}$ & rs2070729 & $5 q 31.1$ & 22 \\
\hline MPV & RNF145 & RING finger protein 145 & $E$ & rs10076782 & $5 q 33.3$ & 22 \\
\hline \multirow[t]{2}{*}{ Count } & \multirow[t]{2}{*}{ BAK1 } & \multirow[t]{2}{*}{ Bcl-2 homologous antagonist/killer } & $\mathrm{E}$ & rs1330066 & \multirow[t]{2}{*}{$6 \mathrm{p} 21.31$} & \multirow[t]{2}{*}{$22-24$} \\
\hline & & & AA & rs210134 & & \\
\hline Count & HLA-DOA & $\begin{array}{l}\text { HLA class II histocompatibility an- } \\
\text { tigen, DO } \alpha \text { chain }\end{array}$ & E & rs399604 & $6 p 21.32$ & 22 \\
\hline Count & $H L A-B$ & $\begin{array}{l}\text { HLA class I histocompatibility anti- } \\
\text { gen, B- } 82 \alpha \text { chain }\end{array}$ & $\mathrm{E}$ & rs3819299 & $6 p 22.2$ & 22 \\
\hline Count & LRRC16A & Leucine-rich repeat containing $16 \mathrm{~A}$ & $\mathrm{AA}, \mathrm{E}, \mathrm{HA}$ & rs441460 & $6 p 22.2$ & 22,24 \\
\hline \multirow[t]{2}{*}{ Count } & \multirow[t]{2}{*}{ HBS1L, MYB } & \multirow{2}{*}{$\begin{array}{l}\text { HBS1-like protein, transcriptional } \\
\text { activator Myb }\end{array}$} & $\mathrm{E}$ & rs9399137 & \multirow[t]{2}{*}{$6 q 23.3$} & \multirow[t]{2}{*}{22,24} \\
\hline & & & AA & rs9494145 & & \\
\hline Count & CD36 & $\begin{array}{l}\text { Platelet glycoprotein IV (thrombo- } \\
\text { spondin receptor) }\end{array}$ & $\mathrm{AA}, \mathrm{E}, \mathrm{HA}$ & rs13236689 & $7 q 21.11$ & 24 \\
\hline \multirow{5}{*}{$\begin{array}{l}\text { Count, MPV, } \\
\text { aggregation } \\
\text { with epinephrine }\end{array}$} & \multirow[t]{5}{*}{ PIK3CG } & \multirow{5}{*}{$\begin{array}{l}\text { Phosphoinositol-4,5-biphosphate } \\
\text { 3-kinase (g subunit) }\end{array}$} & $\mathrm{E}$ & rs342293 (MPV) & \multirow[t]{5}{*}{$7 q 22.3$} & \multirow[t]{5}{*}{$22,23,25$} \\
\hline & & & AA & rs342293 (count) & & \\
\hline & & & AA & rs342296 (MPV) & & \\
\hline & & & $E$ & rs342275 (count) & & \\
\hline & & & $E$ & rs342286 (aggregation) & & \\
\hline
\end{tabular}


Genetic Loci Associated with Platelet Traits and Disorders Bunimov et al. 295

Table 2 (Continued)

\begin{tabular}{|c|c|c|c|c|c|c|}
\hline Trait & Gene & Protein & Population & $\begin{array}{l}\text { SNP with lowest } \\
p \text { value for locus } \\
\text { (associated trait) }\end{array}$ & Cytoband & Reference \\
\hline Count & WASL & $\begin{array}{l}\text { Wiskott-Aldrich syndrome-like } \\
\text { protein }\end{array}$ & $\mathrm{E}$ & rs4731120 & $7 q 31.3$ & 22 \\
\hline \multirow{2}{*}{$\begin{array}{l}\text { Aggregation } \\
\text { with ADP }\end{array}$} & \multirow[t]{2}{*}{ SHH } & \multirow[t]{2}{*}{ Sonic hedgehog protein } & $\mathrm{E}$ & rs2363910 & \multirow[t]{2}{*}{$7 q 36.3$} & \multirow[t]{2}{*}{25} \\
\hline & & & AA & rs6943029 & & \\
\hline Count & ZFPM2 & Zinc finger protein ZFPM2 & $E$ & rs6993770 & $8 q 23.1$ & 22 \\
\hline Count & PLEC1 & Plectin & $\mathrm{E}$ & rs6995402 & $8 q 24.3$ & 22 \\
\hline Count & CDKN2A & $\begin{array}{l}\text { Cyclin-dependent kinase inhibitor } \\
2 \mathrm{~A} \text {, isoform } 4\end{array}$ & $\mathrm{E}$ & rs3731211 & $9 p 21.3$ & 22 \\
\hline MPV & DOCK8 & $\begin{array}{l}\text { Dedicator of cytokinesis } \\
\text { protein } 8\end{array}$ & $\mathrm{E}$ & rs10813766 & $9 p 24.3$ & 22 \\
\hline Count & AK3 & $\begin{array}{l}\text { GTP:AMP phosphor-transferase, } \\
\text { mitochondrial }\end{array}$ & $\mathrm{E}$ & rs409801 & $9 q 24.1$ & 22 \\
\hline Count & $R C L 1$ & $\begin{array}{l}\text { RNA 3'-terminal phosphate } \\
\text { cyclase-like protein }\end{array}$ & $\mathrm{E}$ & rs13300663 & $9 q 24.1$ & 22 \\
\hline Count & BRD3 & Bromodomain-containing protein 3 & $\mathrm{E}$ & rs11789898 & $9 q 34.2$ & 22 \\
\hline \multirow{5}{*}{$\begin{array}{l}\text { Count, MPV, } \\
\text { aggregation } \\
\text { with } \\
\text { epinephrine }\end{array}$} & \multirow[t]{5}{*}{ JMJD1C } & \multirow{5}{*}{$\begin{array}{l}\text { Probable JmjC domain-containing } \\
\text { histone demethylation protein } 2 \mathrm{C}\end{array}$} & $\mathrm{E}$ & rs7075195 (MPV) & \multirow[t]{5}{*}{$10 q 21.2-10 q 21.3$} & \multirow[t]{5}{*}{$22-25$} \\
\hline & & & $\mathrm{E}$ & rs10761731 (count) & & \\
\hline & & & AA & rs7896518 (count) & & \\
\hline & & & $\mathrm{E}$ & $\begin{array}{l}\text { rs10761741 } \\
\text { (aggregation) }\end{array}$ & & \\
\hline & & & AA & $\begin{array}{l}\text { rs2893923 } \\
\text { (aggregation) }\end{array}$ & & \\
\hline \multirow{2}{*}{$\begin{array}{l}\text { Aggregation } \\
\text { with } \\
\text { epinephrine }\end{array}$} & \multirow[t]{2}{*}{$A D R A 2 A$} & \multirow[t]{2}{*}{ Alpha-2A adrenergic receptor } & $\mathrm{E}$ & rs4311994 & \multirow[t]{2}{*}{$10 q 25.2$} & \multirow[t]{2}{*}{25} \\
\hline & & & AA & rs869244 & & \\
\hline \multirow{2}{*}{$\begin{array}{l}\text { Aggregation } \\
\text { with ADP }\end{array}$} & \multirow[t]{2}{*}{ MRVI1 } & \multirow[t]{2}{*}{ Protein MRVI1 } & $\mathrm{E}$ & rs7940646 & \multirow[t]{2}{*}{$11 \mathrm{p} 15.4$} & \multirow[t]{2}{*}{25} \\
\hline & & & AA & rs1874445 & & \\
\hline MPV & BET1L & BET1-like protein & $E$ & rs11602954 & $11 \mathrm{p} 15.5$ & 23 \\
\hline Count, MPV & PSMD13 & $\begin{array}{l}26 S \text { proteasome non-ATPase } \\
\text { regulatory subunit } 13\end{array}$ & $E$ & $\begin{array}{l}\text { rs17655730 (MPV), } \\
\text { rs505404 (count) }\end{array}$ & $11 \mathrm{p} 15.5$ & 22 \\
\hline Count & FEN1 & Flap endonuclease 1 & $\mathrm{E}$ & rs4246215 & $11 q 12.2$ & 22 \\
\hline Count & $B A D$ & $\mathrm{Bcl} 2$ antagonist of cell death & $\mathrm{AA}, \mathrm{E}, \mathrm{HA}$ & rs477895 & $11 q 13.1$ & 24 \\
\hline Count & $C B L$ & E3 ubiquitin-protein ligase CBL & $\mathrm{E}$ & rs4938642 & $11 q 23.3$ & 22 \\
\hline MPV & MLSTD1 & Fatty acyl-CoA reductase 2 & $\mathrm{E}$ & rs2015599 & $12 \mathrm{p} 11.22$ & 22 \\
\hline Count, MPV & $C D 9, V W F$ & $\begin{array}{l}\text { CD9 antigen, von Willebrand } \\
\text { factor }\end{array}$ & $\mathrm{E}$ & $\begin{array}{l}\text { rs1558324 (MPV), } \\
\text { rs7342306 (count) }\end{array}$ & $12 p 13.31$ & 22 \\
\hline Count, MPV & $\begin{array}{l}\text { PTGES3, } \\
\text { BAZ2A }\end{array}$ & $\begin{array}{l}\text { Prostaglandin E synthase } 3 \text {, bro- } \\
\text { modomain adjacent to zinc finger } \\
\text { domain protein } 2 \mathrm{~A}\end{array}$ & $\mathrm{E}$ & $\begin{array}{l}\text { rs2950390 (MPV), } \\
\text { rs941207 (count) }\end{array}$ & $12 q 13.3$ & 22 \\
\hline MPV & $\begin{array}{l}\text { COPZ1, NFE2, } \\
\text { CBX5 }\end{array}$ & $\begin{array}{l}\text { Coatomer subunit zeta-1, } \\
\text { transcription factor NF-E2 } 45 \text { kDa } \\
\text { subunit, chromobox protein } \\
\text { homolog } 5\end{array}$ & $\mathrm{E}$ & rs10876550 & $12 q 13.13$ & 22 \\
\hline Count & ATXN2 & Ataxin 2 & $\mathrm{E}$ & rs11065987 & $12 q 24.1$ & 23 \\
\hline Count & PTPN11 & $\begin{array}{l}\text { Tyrosine-protein phosphatase non- } \\
\text { receptor type } 11\end{array}$ & $\mathrm{E}$ & rs11066301 & $12 q 24.1$ & 22,23 \\
\hline Count & $\begin{array}{l}\text { RPH3A, } \\
\text { PTPN11 }\end{array}$ & $\begin{array}{l}\text { Rabphilin-3A, tyrosine-protein } \\
\text { phosphatase nonreceptor } \\
\text { type } 11\end{array}$ & $E$ & rs17824620 & $12 q 24.1$ & 22 \\
\hline Count & ACAD10 & $\begin{array}{l}\text { Acyl-CoA dehydrogenase family } \\
\text { member } 10\end{array}$ & AA & rs6490294 & $12 q 24.12$ & 24 \\
\hline Count & $\mathrm{SH} 2 \mathrm{~B} 3$ & SH2B adapter protein 3 & $E$ & rs3184504 & $12 q 24.12$ & 22 \\
\hline Count, MPV & WDR66 & $\begin{array}{l}\text { WD repeat-containing } \\
\text { protein } 66\end{array}$ & $\mathrm{E}$ & rs7961894 (count, MPV) & $12 q 24.31$ & 22,23 \\
\hline
\end{tabular}


296 Genetic Loci Associated with Platelet Traits and Disorders Bunimov et al.

Table 2 (Continued)

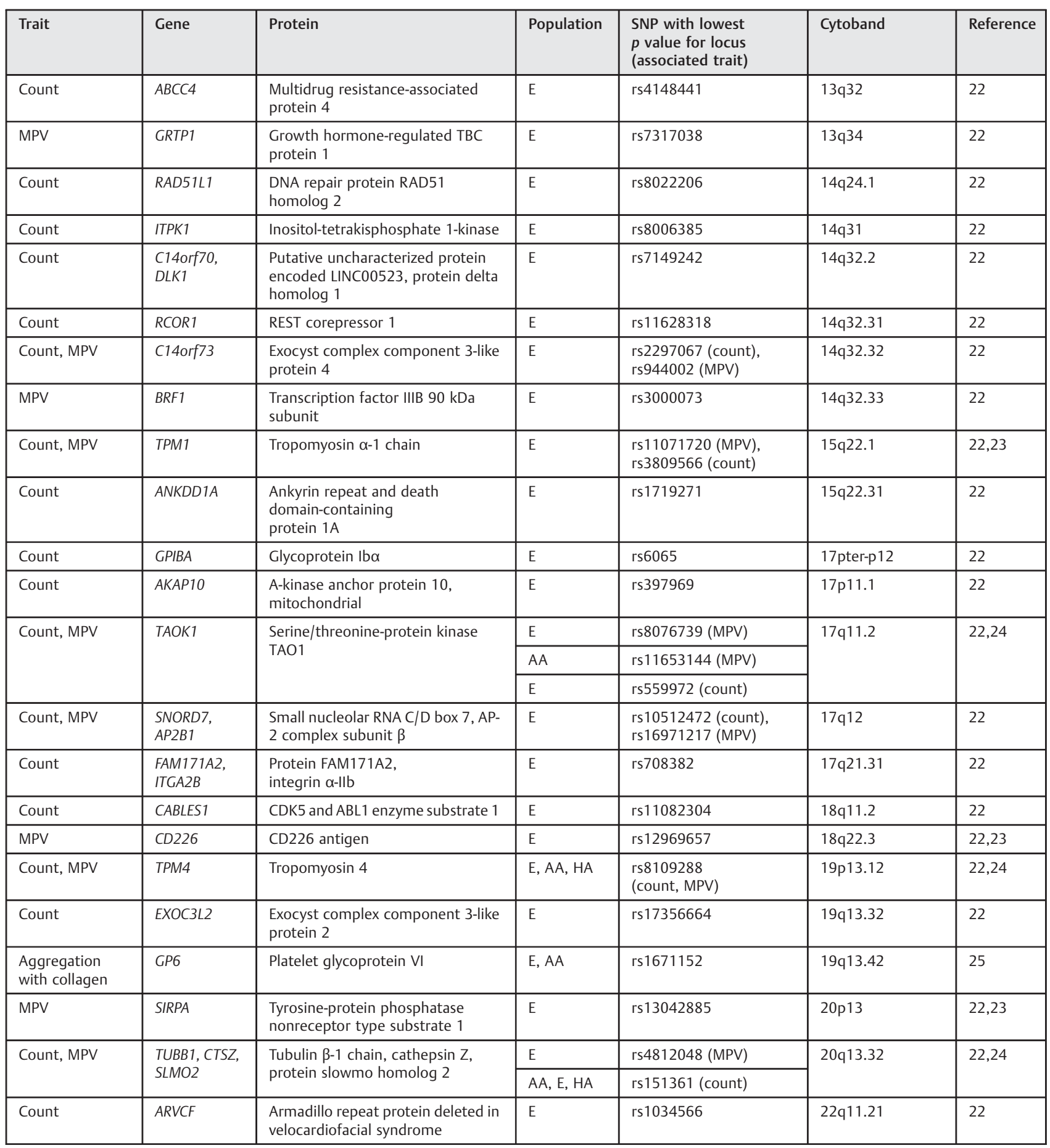

Abbreviations: AA, African Americans; ADP, adenosine diphosphate; CRP, collagen-related peptide; E, European; HA, Hispanic American; MPV, mean platelet volume; SNP, single nucleotide polymorphism.

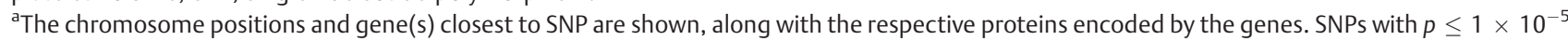
for associations are shown. 
Genetic Loci Associated with Platelet Traits and Disorders Bunimov et al. 297

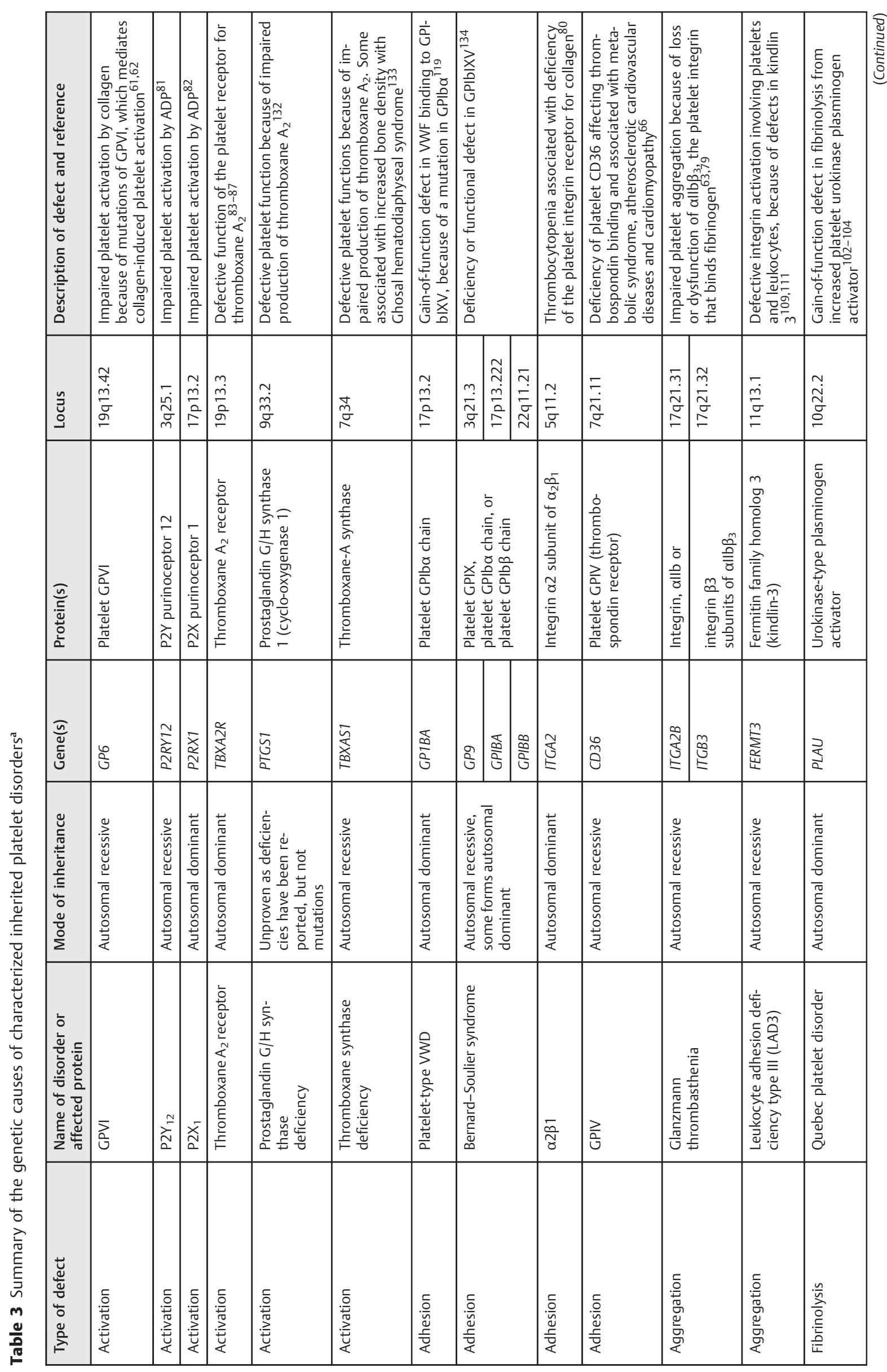




\begin{tabular}{|c|c|c|c|c|c|c|c|c|c|c|c|c|}
\hline 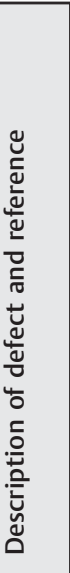 & 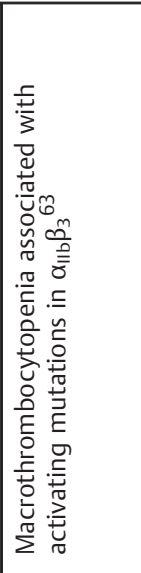 & 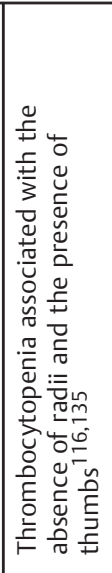 & 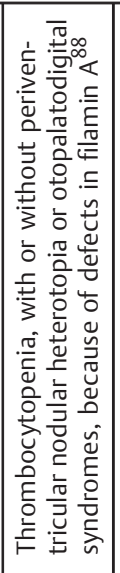 & 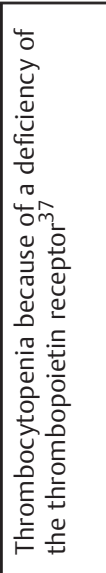 & 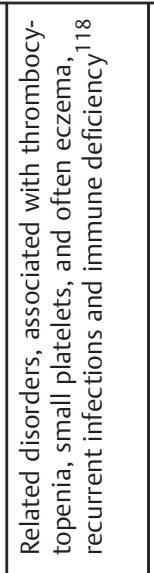 & 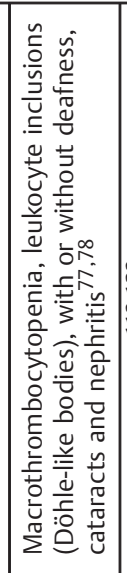 & 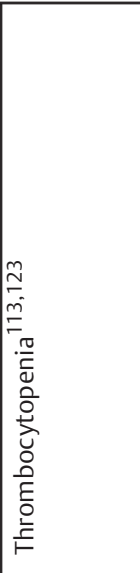 & 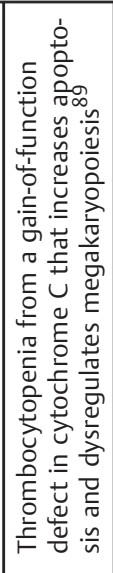 & 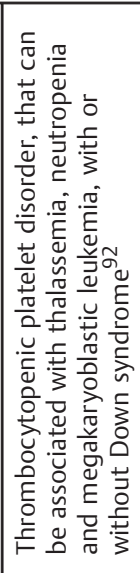 & 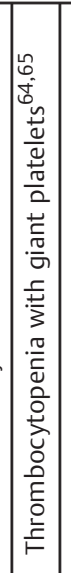 & 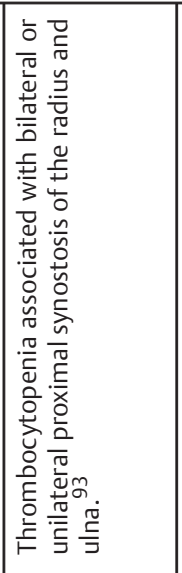 & 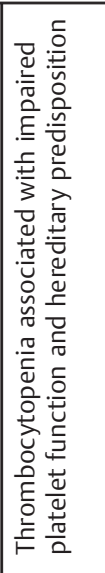 \\
\hline 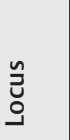 & 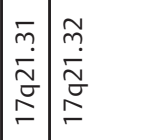 & $\check{\overline{\tilde{z}}}$ & $\begin{array}{l}\stackrel{\infty}{\tilde{y}} \\
\stackrel{x}{x}\end{array}$ & 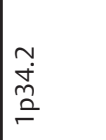 & $\begin{array}{l}\stackrel{n}{\frac{n}{n}} \\
\frac{\bar{x}}{x}\end{array}$ & $\begin{array}{l}m \\
\stackrel{n}{i} \\
\tilde{N}\end{array}$ & $\begin{array}{l}\bar{i} \\
\bar{a} \\
\stackrel{a}{a}\end{array}$ & $\frac{m}{n} \frac{m}{n}$ & $\begin{array}{l}\stackrel{n}{\frac{n}{n}} \\
\frac{\bar{n}}{x}\end{array}$ & $\mid \begin{array}{c}\tilde{n} \\
\tilde{m} \\
\tilde{D} \\
\tilde{N}\end{array}$ & $\begin{array}{l}n \\
\frac{n}{2} \\
\frac{n}{n}\end{array}$ & $\begin{array}{l}\stackrel{N}{\tilde{N}} \\
\underset{\tilde{N}}{\bar{N}}\end{array}$ \\
\hline $\begin{array}{l}\frac{\pi}{n} \\
\frac{\bar{\pi}}{\pi} \\
\vdots \\
\frac{0}{2}\end{array}$ & 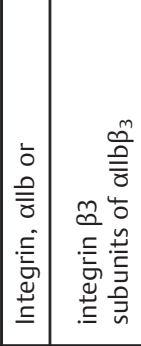 & 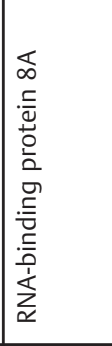 & 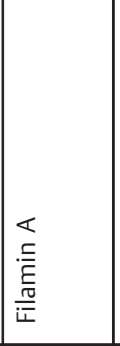 & 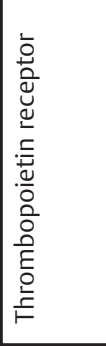 & 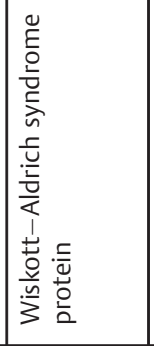 & 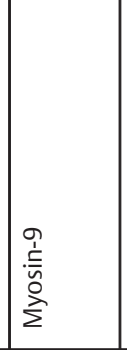 & 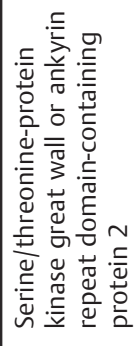 & 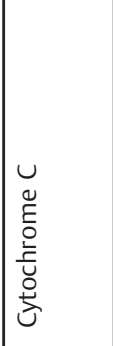 & 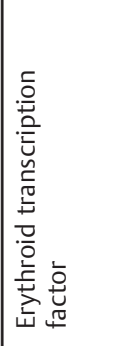 & 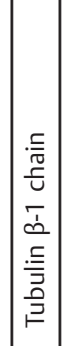 & 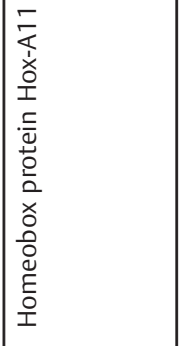 & 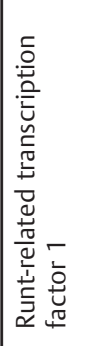 \\
\hline 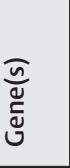 & 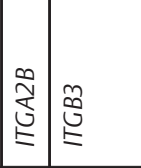 & 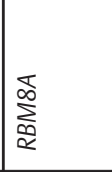 & $\sum_{i}^{\pi}$ & $\overrightarrow{\frac{a}{z}}$ & $\frac{u}{3}$ & 愛 & 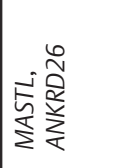 & ¿ & $\frac{1}{\frac{1}{2}}$ & 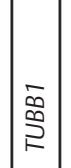 & 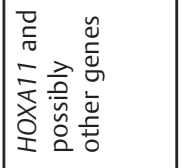 & 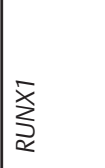 \\
\hline 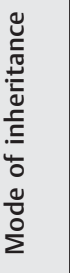 & 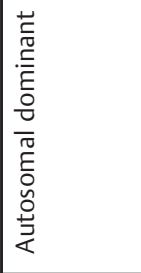 & 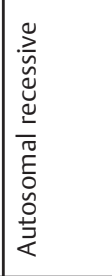 & 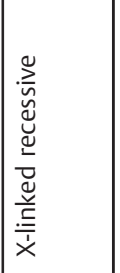 & 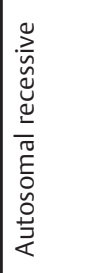 & 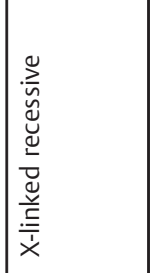 & 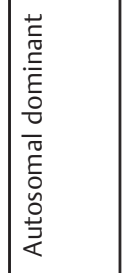 & 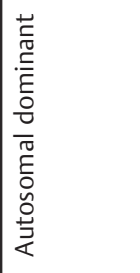 & 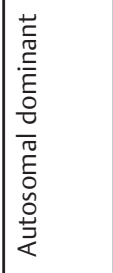 & 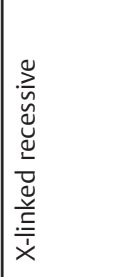 & 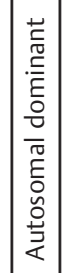 & 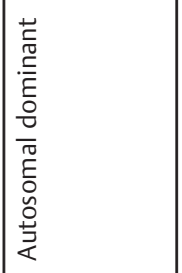 & 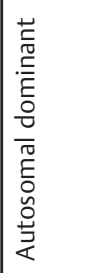 \\
\hline 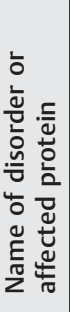 & 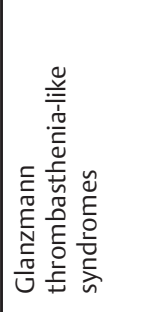 & 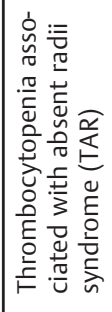 & 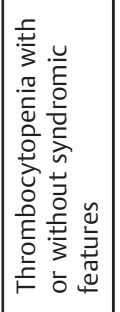 & 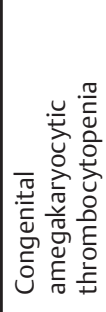 & 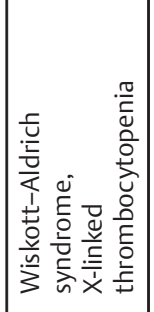 & 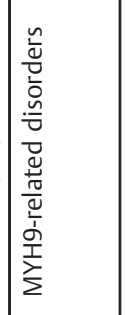 & 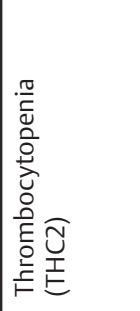 & 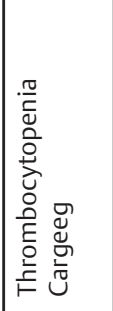 & 妾 & 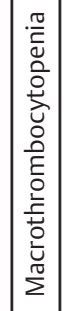 & 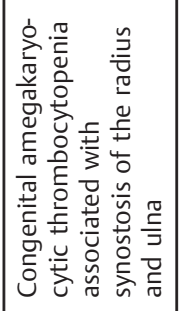 & 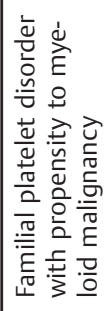 \\
\hline 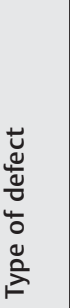 & 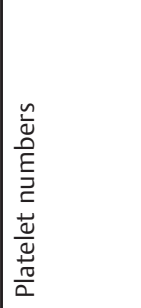 & 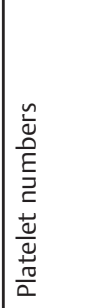 & 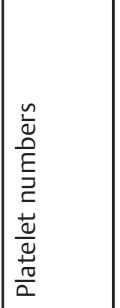 & 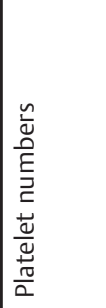 & 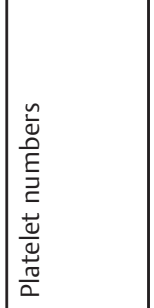 & 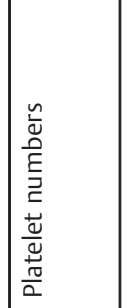 & 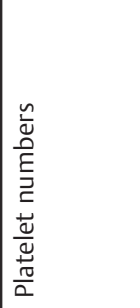 & 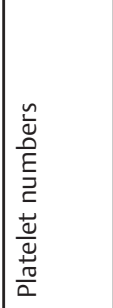 & 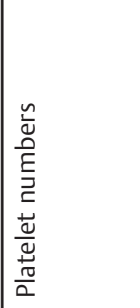 & 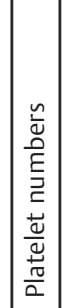 & 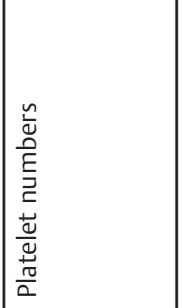 & 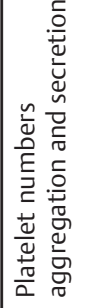 \\
\hline
\end{tabular}




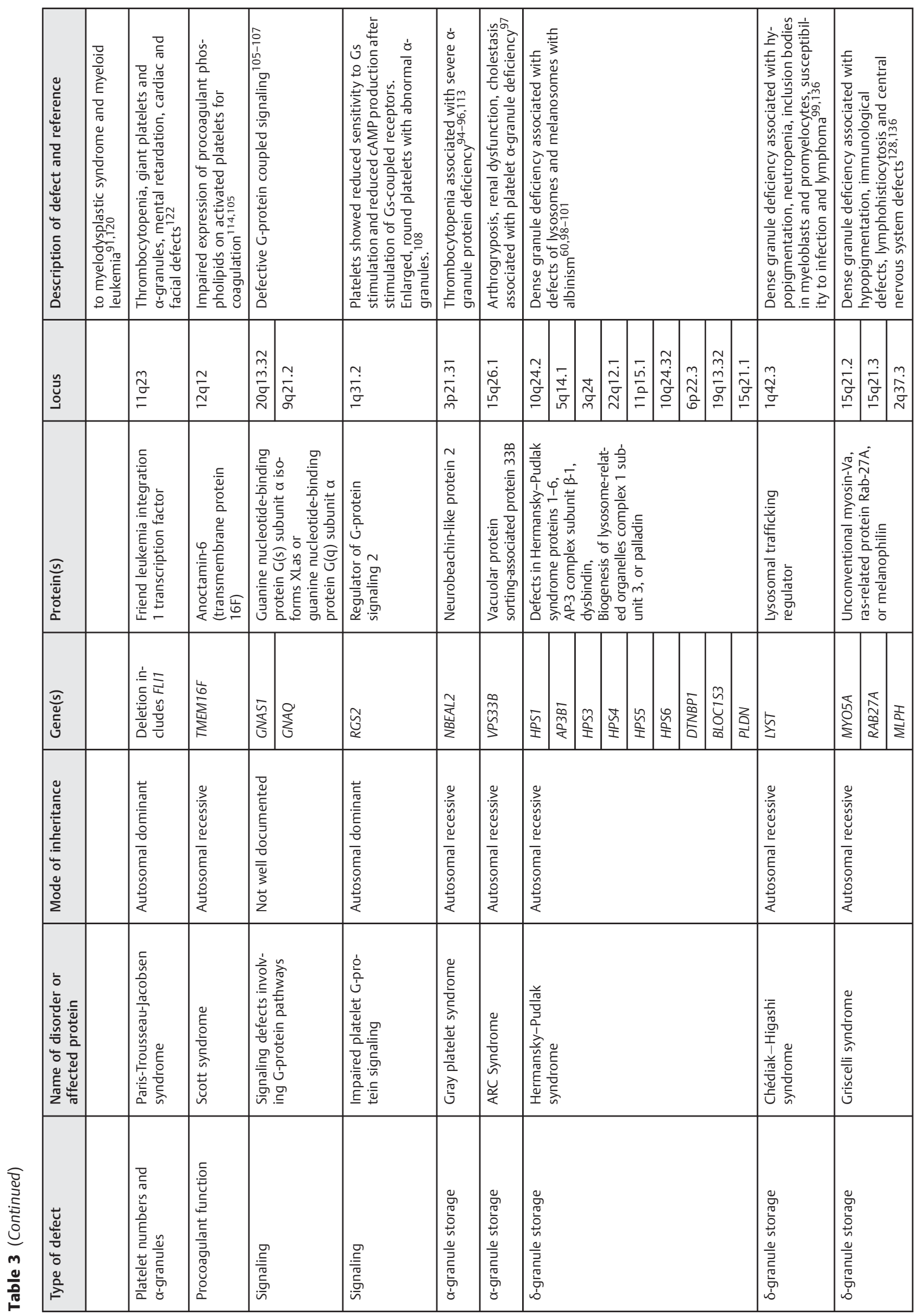

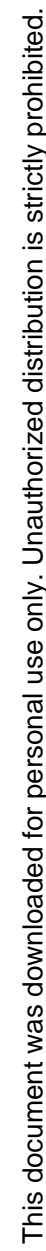




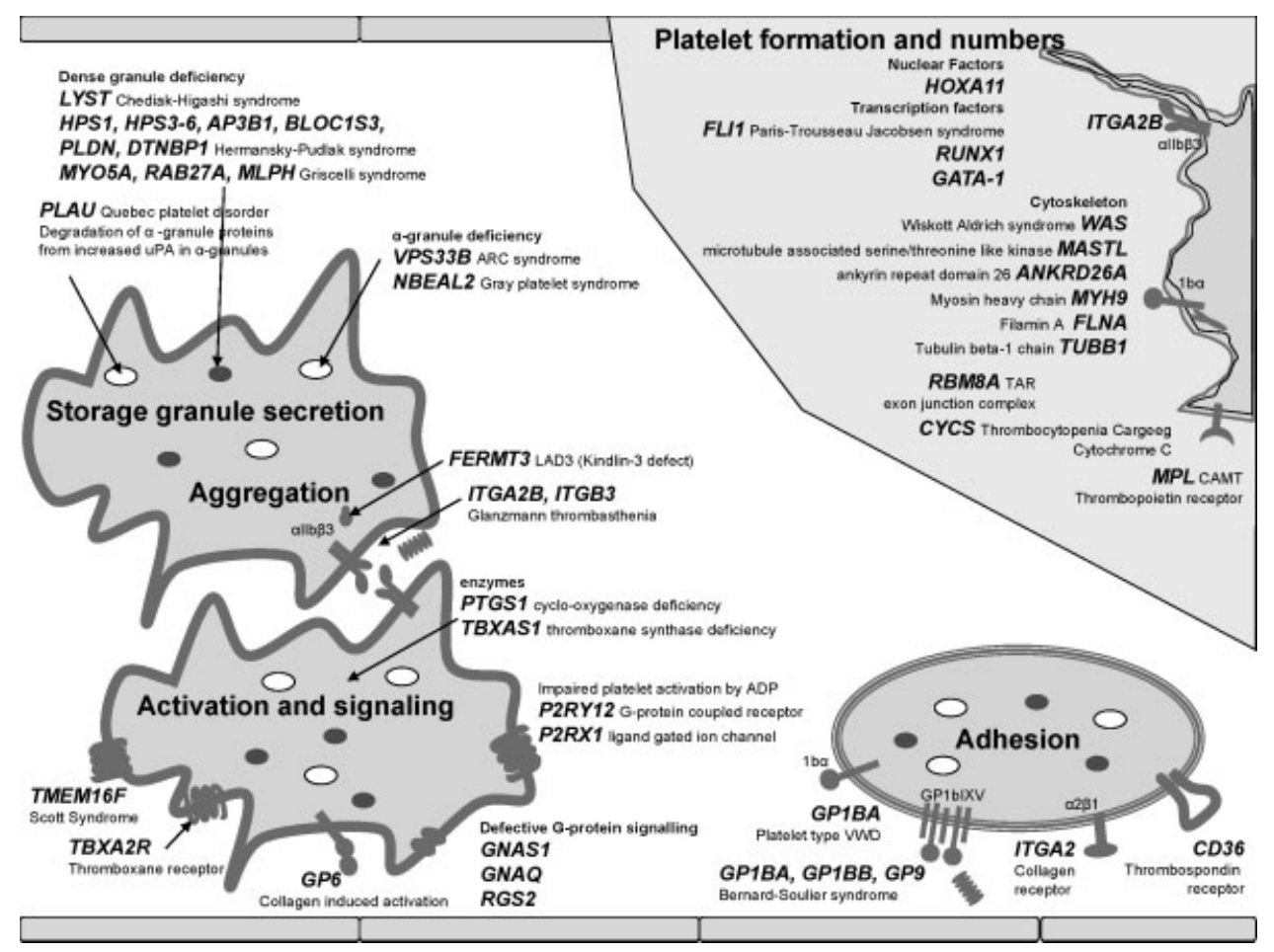

Fig. 1 Schematic representation of the genetic mutations that have been identified to cause platelet function disorders. Affected proteins and resulting disorders are indicated on the diagram, at the point along the pathway of platelet function (from platelet birth to adhesion, activation, and aggregation) that is disrupted.

activated receptor 1 (the thrombin receptor), ${ }^{44}$ the transcriptional activator $\mathrm{Myb}^{45}$ the ATP-binding cassette transporter A1 $\mathrm{ABCA} 1,{ }^{46}$ the transcription factor NF-E2, ${ }^{47}$ secretory carrierassociated membrane protein $5,{ }^{48}$ von Willebrand factor, the tetraspanin $\mathrm{CD} 9,{ }^{49,50} \mathrm{CD} 226,{ }^{51}$ myocyte-specific enhancer factor $2 \mathrm{C}^{52}$ protein MRVI1, ${ }^{53} \mathrm{E} 3$ ubiquitin-protein ligase $\mathrm{CBL},{ }^{54}$ tyrosine-protein phosphatase nonreceptor type $11,{ }^{55}$ tyrosineprotein phosphatase nonreceptor type substrate $1,{ }^{56}$ and $\mathrm{Bcl}-2$ homologous antagonist/killer. ${ }^{57}$ For many of the genes showing association, there is a need to validate the GWAS data by other experimental models, to verify that the candidate genes influence platelet traits, as has been done for supervillin. ${ }^{28}$ Once characterized, candidate genes that are verified to influence platelet traits will provide attractive targets for investigations of the causes of unidentified bleeding disorders.

At present, the knowledge on associations has not reached the point where genotyping can be used to predict an individual's platelet "reactivity" in function tests. It is also important to recognize that GWAS provides information on the genetic causes of variability, but this technique is unlikely to identify rare causes of variability and it will not identify the genes or miRNA with important roles in platelet function if the genetic sequence has little or no variability between subjects.

\section{Gene Defects in Characterized Hereditary Disorders of Platelet Numbers and/or Function}

There has been significant progress in finding the molecular defect of inherited platelet disorders, particularly for rare disorders, including those associated with syndromic features, as summarized in - Table 3 and illustrated in - Fig. $\mathbf{1}^{58-60}$ Nonetheless, only a few of the genes identified to contain mutations in persons with inherited defects of platelet function overlap the genes that show a significant association to platelet "reactivity" in other subjects (-Tables 1-3). Such an overlap is evident in the platelet disorders that are associated with mutations in the genes encoding glycoprotein (GP) $\mathrm{VI},{ }^{61,62}$ platelet GPIb $\alpha,{ }^{59,60}$ integrin $\alpha \mathrm{IIb},{ }^{59,60,63}$ tubulin $\beta-1$ chain, ${ }^{64,65}$ and the thrombospondin receptor. ${ }^{66}$ Nonetheless, there may be important associations with a disease that are not yet discovered, as recent prospective cohort studies indicate that most individuals with bleeding problems from suspected inherited platelet function disorders ( $>90 \%$ ) and impaired platelet aggregation and/or dense granule release have uncharacterized defects. $^{33,67,68}$ There are many potential candidate genes for uncharacterized, inherited platelet disorders, given the many genes transcribed by megakaryocytes and the large number of proteins found in platelets. ${ }^{6,8-11,69-74}$

Genetic mutations resulting in characterized inherited platelet disorders have been identified to alter various aspects of platelets, including their circulating numbers and hemostatic function ( - Fig. 1). Perhaps not surprisingly, most of the mutations are in the genes that have well-known, and important roles in regulating platelet numbers and/or function. ${ }^{59,60}$ Some are associated with thrombocytopenias, with or without changes to platelet shape and volume. ${ }^{75,76}$ As a comprehensive review of the diagnosis and management of all characterized inherited platelet disorders is beyond the scope of this review, readers interested in information on 
specific disorders are encouraged to read the references cited for different conditions.

Mechanistically, the characterized defects are difficult to classify into disorders of number or function as some affect both. The defects involve proteins found in several different compartments within platelets, such as the following: (1) the cytoskeleton (e.g., MYH9-related disorders ${ }^{77,78}$ and $\beta 1$-tubulin defects ${ }^{64,65}$ ); (2) platelet membranes (e.g., the membrane receptor for von Willebrand factor, GPIbIXV, in BernardSoulier syndrome and platelet type von Willebrand disease $^{59,60}$; the fibrinogen receptor $\alpha$ IIb $\beta 3$ in Glanzmann thrombasthenia and the thrombocytopenic disorders associated with gain-of-function defects in this receptor ${ }^{59,60,79}$; the platelet integrin receptor for collagen, $\alpha 2 \beta 1^{80}$; the thrombospondin receptor, GPIV ${ }^{66}$; the membrane receptors for agonist stimulation, GPVI, ${ }^{61,62} \mathrm{P}_{2} \mathrm{Y}_{12},{ }^{81} \mathrm{P}_{2} \mathrm{X}_{1},{ }^{82}$ the TXA2 receptor, ${ }^{83-87}$ among others; the membrane receptor for thrombopoietin in congenital amegakaryocytic thrombocytopenia ${ }^{37}$ ); (3) the region of platelets linking membrane receptors and cytoskeletal proteins (e.g., filamin A defects) ${ }^{88}$; (4) mitochondria (e.g., cytochrome C, which influences platelet apoptosis) ${ }^{89}$; (5) enzymes in the cytosol (e.g., thromboxane-A synthase ${ }^{90}$ ); and (6) the nucleus, in the case of factors that regulate megakaryocyte gene expression, such as RUNX1, ${ }^{91}$ GATA-1, ${ }^{92}$ and HOXA11 ${ }^{93}$ (see - Fig. 1 and - Table 3). Additionally, some disorders are caused by mutations in the genes that affect the biogenesis of $\alpha$ granules $^{94-97}$ and dense granules. ${ }^{98-101}$ A unique copy number variation mutation, causing overexpression of the $\alpha$ granule protein urokinase-type plasminogen activator by megakaryocytes in Quebec platelet disorder, leads to plasmin-mediated degradation of other stored $\alpha$-granule proteins and a gain-of-function defect in clot lysis. ${ }^{102-104}$

The disorders that alter platelet surface receptors can impair platelet function in adhesion or aggregation, alter platelet interactions with collagen, von Willebrand factor, or other ligands ( $\mathbf{- F i g . 1}$ and $\mathbf{-}$ Table $\mathbf{3}$ ), or alter the process of platelet activation by ADP, collagen or TXA2, and agonistinduced signaling (-Fig. 1 and - Table 3). Recently, a mutation of the transmembrane protein $16 \mathrm{~F}, \mathrm{a} \mathrm{Ca}^{2+}$-activated chloride channel, was identified as the cause of the defective, agonist-induced scrambling of phospholipids and impaired membrane activation and procoagulant function of Scott syndrome. Platelet signaling, which is important for activation induced by agonists and platelet interactions with adhesive ligands, is impaired by mutations in genes encoding G proteins ${ }^{105-107}$ and in proteins that regulate G-protein signaling. ${ }^{108}$ Inside-out integrin activation is impaired by mutation in the gene for kindlin-3, an intracellular protein that interacts with $\beta$ integrins. ${ }^{109}$

\section{Inherited Platelet Disorders: Current Information on Modes of Inheritance}

Among the characterized inherited platelet abnormalities, autosomal recessive platelet disorders represent a rare but important cause of bleeding (prevalence approximately $1: 10^{6}$ or less). ${ }^{60,110}$ Some of these recessive platelet disorders derive from mutations in genes that encode proteins that are important for platelet production (e.g., MPL, the thrombopoietin receptor), ${ }^{37,76}$ adhesion or aggregation (e.g., glycoprotein IbIX in Bernard-Soulier syndrome ${ }^{59,60} ; \alpha \operatorname{IIb} \beta_{3}$ in Glanzmann thrombasthenia ${ }^{59,60}$; and kindlin-3 in persons with impaired platelet integrin function and leukocyte adhesion defects ${ }^{59,109,111}$ ), agonist responses (e.g., ADP receptor $\mathrm{P}_{2} \mathrm{Y}_{12}$, GPVI, and thromboxane synthase), ${ }^{61,62,81,90,112}$ and granule protein storage (e.g., NBEAL2 in gray platelet syndrome) ${ }^{94-96,113}$ (- Table 3). The recessively inherited platelet disorders also include conditions such as Scott syndrome, ${ }^{114,115}$ thrombocytopenia with absent radii syndrome, ${ }^{116}$ and syndromic disorders associated with $\delta$ granule deficiency ( - Table 3 ). ${ }^{97-101,117}$

$\mathrm{X}$-linked platelet disorders are uncommon and include thrombocytopenia associated with GATA-1 mutations, ${ }^{92}$ Wiskott-Aldrich syndrome and the related condition, Xlinked thrombocytopenia, ${ }^{118}$ in addition to the syndromic and nonsyndromic thrombocytopenias associated with filamin A defects ${ }^{59,88}$ (- Table 3).

Autosomal dominant platelet disorders are the most prevalent of inherited platelet disorders and their causes include mutations in diverse genes that are important for fibrinolysis (e.g., PLAU in Quebec platelet disorder), ${ }^{102-104}$ platelet adhesion (e.g., activating mutations of the gene for GPoIIb $\beta_{3}$, and GPIb $\alpha$, and $\alpha_{2} \beta_{1}$ deficiency), ${ }^{60,63,80,119}$ agonist response (e.g., $\mathrm{P}_{2 \mathrm{X}_{1}}{ }^{82}$ and TXA2 receptor ${ }^{83,84,87}$ ), the platelet cytoskeleton (e.g., MYH9-related disorders), ${ }^{77,78}$ transcriptional regulation (e.g., $R U N X 1),{ }^{91,120}$ or other platelet traits, ${ }^{80,121-123}$ including apoptotic pathways that influence platelet numbers 89 (-Table 3). Defects in the platelet function from mutations in the gene encoding the TXA2 receptor have been reported in individuals heterozygous for receptor mutations, ${ }^{84,87}$ although some have been homozygous for mutations. ${ }^{86}$

Most patients with uncharacterized inherited platelet function disorders have "secretion defects" (also called "release" or "activation" defects) that impair platelet function in aggregation and/or dense granule release assays, often with multiple (but not necessarily all) agonists. ${ }^{33,34,67,68,124-126} \mathrm{~A}$ comprehensive study of the genetic causes of inherited platelet secretion defects has never been undertaken. Inherited secretion defects include $\delta$-granule deficiency, which can result from characterized, autosomal recessive, syndromic disorders associated with hypopigmentation (e.g., Hermansky-Pudlak syndrome, Chédiak-Higashi syndrome, and Griscelli syndrome) $)^{97,100,127,128}$ or uncharacterized, nonsyndromic autosomal dominant causes $\left({ }^{79,80,127,129}\right.$ and Hayward, unpublished observations). Impaired platelet secretion has been reported in individuals who are heterozygous for disease-causing P2RY12 mutations (gene for the ADP receptor $\mathrm{P} \mathrm{Y}_{12}$ ), who have impaired ADP aggregation. ${ }^{130}$ However, P2RY12 mutations could be an infrequent cause of hereditary secretion defects as many individuals with secretion defects have normal ADP aggregation responses. ${ }^{34}$

\section{Summary}

In recent years, GWAS have become a powerful tool for identifying new genetic factors involved in human diseases 
and variability in the general population, including platelet function. ${ }^{13}$ GWAS, and meta-analyses of GWAS data, have provided new information on the genes that influence platelet function and traits (refer to - Tables 1 and $\mathbf{2}$ ). Nonetheless, some caution is advised as many of the associated genes have not been tested for influence on platelet traits using other models (e.g., mouse knockouts ${ }^{28}$ and zebrafish morpholinos ${ }^{131}$ ) to validate their importance to platelet function and other platelet traits. It is likely that platelet function is influenced by many factors, including genetic background, ethnicity, gender and environment, and exposures to drugs that inhibit platelet function. Although the characterization of several disorders with an altered platelet phenotype has provided important new insights on the genes that influence platelet traits, the causes of most inherited platelet "secretion defects" still need to be thoughtfully characterized. Technical advances in molecular analysis of gene linkage and genomic sequences (e.g., full genome and exome sequencing) will facilitate the discovery of the disease-causing mutations of inherited platelet function disorders and increase our understanding of the genetic loci that influence platelet physiology and pathology.

\section{Funding}

Catherine Hayward is the recipient of a Heart and Stroke Foundation of Ontario Career Investigator Award. The work was supported by grants from the Canadian Institutes for Health Research (MOP 97942) and the Canadian Hemophilia Society.

\section{Conflict of Interest}

The authors have no conflicts of interest to disclose.

\section{References}

1 Gresele P, Page CP, Fuster V, Vermylen J. Platelets in Thrombotic and Non-thrombotic Disorders. Cambridge, UK: Cambridge University Press; 2002:1-1124

2 Michelson AD. Platelets. 3rd ed. Philadelphia, PA: Elsevier/Academic Press; 2013 (in press)

3 Marder VJ, Aird WC, Bennett JS, Schulman S, White GC II. Hemostasis and Thrombosis: Basic Principles and Clinical Practice. 6th ed. Philadelphia, PA: Lippincott Williams and Wilkins; 2012:1-1592

4 Rowley JW, Oler AJ, Tolley ND, et al. Genome-wide RNA-seq analysis of human and mouse platelet transcriptomes. Blood 2011;118(14):e101-e111

5 Gnatenko DV, Dunn JJ, Schwedes J, Bahou WF. Transcript profiling of human platelets using microarray and serial analysis of gene expression (SAGE). Methods Mol Biol 2009;496:245-272

6 Senzel L, Gnatenko DV, Bahou WF. The platelet proteome. Curr Opin Hematol 2009;16(5):329-333

7 Bahou WF. Platelet systems biology using integrated genetic and proteomic platforms. Thromb Res 2012;129(Suppl 1):S38-S45

8 García A, Prabhakar S, Brock CJ, et al. Extensive analysis of the human platelet proteome by two-dimensional gel electrophoresis and mass spectrometry. Proteomics 2004;4(3):656-668

9 García A, Prabhakar S, Hughan S, et al. Differential proteome analysis of TRAP-activated platelets: involvement of DOK-2 and phosphorylation of RGS proteins. Blood 2004;103(6):2088-2095
10 García A, Zitzmann N, Watson SP. Analyzing the platelet proteome. Semin Thromb Hemost 2004;30(4):485-489

11 Watson SP, Bahou WF, Fitzgerald D, Ouwehand W, Rao AK, Leavitt AD; ISTH Platelet Physiology Subcommittee. Mapping the platelet proteome: a report of the ISTH Platelet Physiology Subcommittee. J Thromb Haemost 2005;3(9):2098-2101

12 Gaxiola B, Friedl W, Propping P. Epinephrine-induced platelet aggregation. A twin study. Clin Genet 1984;26(6):543-548

13 Kunicki TJ, Williams SA, Nugent DJ. Genetic variants that affect platelet function. Curr Opin Hematol 2012;19(5):371-379

14 Ferreira MA, Hottenga JJ, Warrington NM, et al. Sequence variants in three loci influence monocyte counts and erythrocyte volume. Am J Hum Genet 2009;85(5):745-749

15 Meisinger C, Prokisch H, Gieger C, et al. A genome-wide association study identifies three loci associated with mean platelet volume. Am J Hum Genet 2009;84(1):66-71

16 Guerrero JA, Rivera J, Quiroga T, et al. Novel loci involved in platelet function and platelet count identified by a genomewide study performed in children. Haematologica 2011;96(9): 1335-1343

17 Mathias RA, Kim Y, Sung $\mathrm{H}$, et al. A combined genome-wide linkage and association approach to find susceptibility loci for platelet function phenotypes in European American and African American families with coronary artery disease. BMC Med Genomics 2010;3:22

18 Kamatani Y, Matsuda K, Okada Y, et al. Genome-wide association study of hematological and biochemical traits in a Japanese population. Nat Genet 2010;42(3):210-215

19 Soranzo N, Rendon A, Gieger C, et al. A novel variant on chromosome 7q22.3 associated with mean platelet volume, counts, and function. Blood 2009;113(16):3831-3837

20 Yang Q Kathiresan S, Lin JP, Tofler GH, O'Donnell CJ. Genomewide association and linkage analyses of hemostatic factors and hematological phenotypes in the Framingham Heart Study. BMC Med Genet 2007;8(Suppl 1):S12

21 Lo KS, Wilson JG, Lange LA, et al. Genetic association analysis highlights new loci that modulate hematological trait variation in Caucasians and African Americans. Hum Genet 2011;129(3): 307-317

22 Gieger C, Radhakrishnan A, Cvejic A, et al. New gene functions in megakaryopoiesis and platelet formation. Nature 2011;480(7376): 201-208

23 Soranzo N, Spector TD, Mangino M, et al. A genome-wide metaanalysis identifies 22 loci associated with eight hematological parameters in the HaemGen consortium. Nat Genet 2009; 41(11):1182-1190

24 Qayyum R, Snively BM, Ziv E, et al. A meta-analysis and genomewide association study of platelet count and mean platelet volume in African Americans. PLoS Genet 2012;8(3):e1002491

25 Johnson AD, Yanek LR, Chen MH, et al. Genome-wide metaanalyses identifies seven loci associated with platelet aggregation in response to agonists. Nat Genet 2010;42(7):608-613

26 Goodall AH, Burns P, Salles I, et al; Bloodomics Consortium. Transcription profiling in human platelets reveals LRRFIP1 as a novel protein regulating platelet function. Blood 2010;116(22): 4646-4656

27 Snoep JD, Gaussem P, Eikenboom JC, et al. The minor allele of GP6 $\mathrm{T} 13254 \mathrm{C}$ is associated with decreased platelet activation and a reduced risk of recurrent cardiovascular events and mortality: results from the SMILE-Platelets project. J Thromb Haemost 2010;8(11):2377-2384

28 Edelstein LC, Luna EJ, Gibson IB, et al. Human genome-wide association and mouse knockout approaches identify platelet supervillin as an inhibitor of thrombus formation under shear stress. Circulation 2012;125(22):2762-2771

29 Nagalla S, Shaw C, Kong X, et al. Platelet microRNA-mRNA coexpression profiles correlate with platelet reactivity. Blood 2011;117(19):5189-5197 
30 Bray PF, Mathias RA, Faraday N, et al. Heritability of platelet function in families with premature coronary artery disease. J Thromb Haemost 2007;5(8):1617-1623

31 Herrera-Galeano JE, Becker DM, Wilson AF, et al. A novel variant in the platelet endothelial aggregation receptor- 1 gene is associated with increased platelet aggregability. Arterioscler Thromb Vasc Biol 2008;28(8):1484-1490

32 Faraday N, Yanek LR, Yang XP, et al. Identification of a specific intronic PEAR1 gene variant associated with greater platelet aggregability and protein expression. Blood 2011;118(12):3367-3375

33 Hayward CP, Pai M, Liu Y, et al. Diagnostic utility of light transmission platelet aggregometry: results from a prospective study of individuals referred for bleeding disorder assessments. J Thromb Haemost 2009;7(4):676-684

34 Pai M, Wang G, Moffat KA, et al. Diagnostic usefulness of a lumiaggregometer adenosine triphosphate release assay for the assessment of platelet function disorders. Am J Clin Pathol 2011; 136(3):350-358

35 Lo KA, Bauchmann MK, Baumann AP, et al. Genome-wide profiling of H3K56 acetylation and transcription factor binding sites in human adipocytes. PLoS ONE 2011;6(6):e19778

36 Kunicki TJ, Nugent DJ. The genetics of normal platelet reactivity. Blood 2010;116(15):2627-2634

37 Ballmaier M, Germeshausen M. Congenital amegakaryocytic thrombocytopenia: clinical presentation, diagnosis, and treatment. Semin Thromb Hemost 2011;37(6):673-681

38 Hirsch E, Bosco O, Tropel P, et al. Resistance to thromboembolism in PI3Kgamma-deficient mice. FASEB J 2001;15(11):2019-2021

39 Pozgajová M, Sachs UJ, Hein L, Nieswandt B. Reduced thrombus stability in mice lacking the alpha2A-adrenergic receptor. Blood 2006;108(2):510-514

40 Kauskot A, Di Michele M, Loyen S, Freson K, Verhamme P, Hoylaerts MF. A novel mechanism of sustained platelet $\alpha$ IIb $\beta 3$ activation via PEAR1. Blood 2012;119(17):4056-4065

41 Wang W, Gilligan DM, Sun S, Wu X, Reems JA. Distinct functional effects for dynamin 3 during megakaryocytopoiesis. Stem Cells Dev 2011;20(12):2139-2151

42 Jedlitschky G, Cattaneo M, Lubenow LE, et al. Role of MRP4 (ABCC4) in platelet adenine nucleotide-storage: evidence from patients with delta-storage pool deficiencies. Am J Pathol 2010; 176(3):1097-1103

43 Côté GP. Structural and functional properties of the non-muscle tropomyosins. Mol Cell Biochem 1983;57(2):127-146

44 Lang NN, Guðmundsdóttir IJ, Newby DE. Vascular PAR-1: activity and antagonism. Cardiovasc Ther 2011;29(6):349-361

45 García P, Berlanga O, Vegiopoulos A, Vyas P, Frampton J. c-Myb and GATA-1 alternate dominant roles during megakaryocyte differentiation. J Thromb Haemost 2011;9(8):1572-1581

46 Schmitz G, Schambeck CM. Molecular defects in the ABCA1 pathway affect platelet function. Pathophysiol Haemost Thromb 2006;35(1-2):166-174

47 Fock EL, Yan F, Pan S, Chong BH. NF-E2-mediated enhancement of megakaryocytic differentiation and platelet production in vitro and in vivo. Exp Hematol 2008;36(1):78-92

48 Castermans D, Volders K, Crepel A, et al. SCAMP5, NBEA and AMISYN: three candidate genes for autism involved in secretion of large dense-core vesicles. Hum Mol Genet 2010;19(7): 1368-1378

49 Israels SJ, McMillan-Ward EM. Platelet tetraspanin complexes and their association with lipid rafts. Thromb Haemost 2007;98 (5):1081-1087

50 Mangin PH, Kleitz L, Boucheix C, Gachet C, Lanza F. CD9 negatively regulates integrin alphallbbeta 3 activation and could thus prevent excessive platelet recruitment at sites of vascular injury. J Thromb Haemost 2009;7(5):900-902

51 Kojima H, Kanada H, Shimizu S, et al. CD226 mediates platelet and megakaryocytic cell adhesion to vascular endothelial cells. J Biol Chem 2003;278(38):36748-36753
52 Gekas C, Rhodes KE, Gereige LM, et al. Mef2C is a lineagerestricted target of Scl/Tal1 and regulates megakaryopoiesis and B-cell homeostasis. Blood 2009;113(15):3461-3471

53 Antl M, von Brühl ML, Eiglsperger C, et al. IRAG mediates NO/ cGMP-dependent inhibition of platelet aggregation and thrombus formation. Blood 2007;109(2):552-559

54 Buitrago L, Tsygankov A, Sanjay A, Kunapuli SP. Cbl proteins in platelet activation. Platelets 2012;(August):29

55 Derbent M, Öncel Y, Tokel K, et al. Clinical and hematologic findings in Noonan syndrome patients with PTPN11 gene mutations. Am J Med Genet A 2010;152A(11):2768-2774

56 Catani L, Sollazzo D, Ricci F, et al. The CD47 pathway is deregulated in human immune thrombocytopenia. Exp Hematol 2011;39(4):486-494

57 Josefsson EC, James C, Henley KJ, et al. Megakaryocytes possess a functional intrinsic apoptosis pathway that must be restrained to survive and produce platelets. J Exp Med 2011;208(10): 2017-2031

58 Hayward CP, Favaloro EJ. Diagnostic evaluation of platelet disorders: the past, the present, and the future. Semin Thromb Hemost 2009;35(2):127-130

59 Nurden A, Nurden P. Advances in our understanding of the molecular basis of disorders of platelet function. J Thromb Haemost 2011;9(Suppl 1):76-91

60 Nurden AT, Freson K, Seligsohn U. Inherited platelet disorders. Haemophilia 2012;18(Suppl 4):154-160

61 Dumont B, Lasne D, Rothschild C, et al. Absence of collageninduced platelet activation caused by compound heterozygous GPVI mutations. Blood 2009;114(9):1900-1903

62 Hermans C, Wittevrongel C, Thys C, Smethurst PA, Van Geet C, Freson K. A compound heterozygous mutation in glycoprotein $\mathrm{VI}$ in a patient with a bleeding disorder. J Thromb Haemost 2009; 7(8):1356-1363

63 Nurden AT, Pillois X, Fiore M, Heilig R, Nurden P. Glanzmann thrombasthenia-like syndromes associated with Macrothrombocytopenias and mutations in the genes encoding the $\alpha \operatorname{Ilb} \beta 3$ integrin. Semin Thromb Hemost 2011;37(6):698-706

64 Navarro-Núñez L, Teruel R, Antón AI, et al. Rare homozygous status of P43 $\beta 1$-tubulin polymorphism causes alterations in platelet ultrastructure. Thromb Haemost 2011;105(5): 855-863

65 Kunishima S, Kobayashi R, Itoh TJ, Hamaguchi M, Saito H. Mutation of the beta1-tubulin gene associated with congenital macrothrombocytopenia affecting microtubule assembly. Blood 2009; 113(2):458-461

66 Hirano K, Kuwasako T, Nakagawa-Toyama Y, Janabi M, Yamashita S, Matsuzawa Y. Pathophysiology of human genetic CD36 deficiency. Trends Cardiovasc Med 2003;13(4):136-141

67 Castilloux JF, Moffat KA, Liu Y, Seecharan J, Pai M, Hayward CP. A prospective cohort study of light transmission platelet aggregometry for bleeding disorders: is testing native platelet-rich plasma non-inferior to testing platelet count adjusted samples? Thromb Haemost 2011;106(4):675-682

68 Hayward CP, Moffat KA, Castilloux JF, et al. Simultaneous measurement of adenosine triphosphate release and aggregation potentiates human platelet aggregation responses for some subjects, including persons with Quebec platelet disorder. Thromb Haemost 2012;107(4):726-734

69 Gnatenko DV, Perrotta PL, Bahou WF. Proteomic approaches to dissect platelet function: Half the story. Blood 2006;108(13): 3983-3991

70 Gnatenko DV, Zhu W, Bahou WF. Multiplexed genetic profiling of human blood platelets using fluorescent microspheres. Thromb Haemost 2008;100(5):929-936

71 O'Neill EE, Brock CJ, von Kriegsheim AF, et al. Towards complete analysis of the platelet proteome. Proteomics 2002;2(3):288-305

72 Perrotta PL, Bahou WF. Proteomics in platelet science. Curr Hematol Rep 2004;3(6):462-469 
73 Maynard DM, Heijnen HF, Horne MK, White JG, Gahl WA. Proteomic analysis of platelet alpha-granules using mass spectrometry. J Thromb Haemost 2007;5(9):1945-1955

74 Parguiña AF, Rosa I, García A. Proteomics applied to the study of platelet-related diseases: aiding the discovery of novel platelet biomarkers and drug targets. J Proteomics 2012;76(Spec No): 275-286

75 Balduini CL, Pecci A, Norris P. Diagnosis and management of inherited thrombocytopenias. Semin Thromb Hemost 2013; doi: http://dx.doi.org/ 10.1055/s-0032-1333540

76 Hayward CP, Bunimov N. Thrombocytopenic platelet disorders. Semin Thromb Hemost 2011;37(6):617-620

77 Althaus K, Greinacher A. MYH9-related platelet disorders. Semin Thromb Hemost 2009;35(2):189-203

78 Balduini CL, Pecci A, Savoia A. Recent advances in the understanding and management of MYH9-related inherited thrombocytopenias. Br J Haematol 2011;154(2):161-174

79 Nurden AT, Fiore M, Nurden P, Pillois X. Glanzmann thrombasthenia: a review of ITGA2B and ITGB3 defects with emphasis on variants, phenotypic variability, and mouse models. Blood 2011; 118(23):5996-6005

80 Noris P, Guidetti GF, Conti V, et al. Autosomal dominant thrombocytopenias with reduced expression of glycoprotein Ia. Thromb Haemost 2006;95(3):483-489

81 Cattaneo M. The platelet $\mathrm{P}_{2} \mathrm{Y}_{12}$ receptor for adenosine diphosphate: congenital and drug-induced defects. Blood 2011; 117(7):2102-2112

82 Oury C, Toth-Zsamboki E, Van Geet C, et al. A natural dominant negative P2X1 receptor due to deletion of a single amino acid residue. J Biol Chem 2000;275(30):22611-22614

83 Kamae T, Kiyomizu K, Nakazawa T, et al. Bleeding tendency and impaired platelet function in a patient carrying a heterozygous mutation in the thromboxane A2 receptor. J Thromb Haemost 2011;9(5):1040-1048

84 Mumford AD, Dawood BB, Daly ME, et al. A novel thromboxane A2 receptor $\mathrm{D} 304 \mathrm{~N}$ variant that abrogates ligand binding in a patient with a bleeding diathesis. Blood 2010;115(2):363-369

85 Fuse I, Higuchi W, Aizawa Y. Pathogenesis of a bleeding disorder characterized by platelet unresponsiveness to thromboxane A2. Semin Thromb Hemost 2000;26(1):43-45

86 Higuchi W, Fuse I, Hattori A, Aizawa Y. Mutations of the platelet thromboxane A2 (TXA2) receptor in patients characterized by the absence of TXA2-induced platelet aggregation despite normal TXA2 binding activity. Thromb Haemost 1999;82(5):1528-1531

87 Hirata T, Kakizuka A, Ushikubi F, Fuse I, Okuma M, Narumiya S. Arg60 to Leu mutation of the human thromboxane A2 receptor in a dominantly inherited bleeding disorder. J Clin Invest 1994; 94(4):1662-1667

88 Nurden P, Debili N, Coupry I, et al. Thrombocytopenia resulting from mutations in filamin A can be expressed as an isolated syndrome. Blood 2011;118(22):5928-5937

89 Cramer Bordé E, Ouzegdouh Y, Ledgerwood EC, Morison IM. Congenital thrombocytopenia and cytochrome $C$ mutation: a matter of birth and death. Semin Thromb Hemost 2011;37(6): 664-672

90 Geneviève D, Proulle V, Isidor B, et al. Thromboxane synthase mutations in an increased bone density disorder (Ghosal syndrome). Nat Genet 2008;40(3):284-286

91 Michaud J, Wu F, Osato M, et al. In vitro analyses of known and novel RUNX1/AML1 mutations in dominant familial platelet disorder with predisposition to acute myelogenous leukemia: implications for mechanisms of pathogenesis. Blood 2002; 99(4):1364-1372

92 Millikan PD, Balamohan SM, Raskind WH, Kacena MA. Inherited thrombocytopenia due to GATA-1 mutations. Semin Thromb Hemost 2011;37(6):682-689

93 Thompson AA, Nguyen LT. Amegakaryocytic thrombocytopenia and radio-ulnar synostosis are associated with HOXA11 mutation. Nat Genet 2000;26(4):397-398
94 Kahr WH, Hinckley J, Li L, et al. Mutations in NBEAL2, encoding a BEACH protein, cause gray platelet syndrome. Nat Genet 2011; 43(8):738-740

95 Gunay-Aygun M, Falik-Zaccai TC, Vilboux T, et al. NBEAL2 is mutated in gray platelet syndrome and is required for biogenesis of platelet $\alpha$-granules. Nat Genet 2011;43(8):732-734

96 Albers CA, Cvejic A, Favier R, et al. Exome sequencing identifies NBEAL2 as the causative gene for gray platelet syndrome. Nat Genet 2011;43(8):735-737

97 Abu-Sa'da O, Barbar M, Al-Harbi N, Taha D. Arthrogryposis, renal tubular acidosis and cholestasis (ARC) syndrome: two new cases and review. Clin Dysmorphol 2005;14(4):191-196

98 Meng R, Wang Y, Yao Y, et al. SLC35D3 delivery from megakaryocyte early endosomes is required for platelet dense granule biogenesis and is differentially defective in Hermansky-Pudlak syndrome models. Blood 2012;120(2):404-414

99 Masliah-Planchon J, Darnige L, Bellucci S. Molecular determinants of platelet delta storage pool deficiencies: an update. $\mathrm{Br} \mathrm{J}$ Haematol 2013;160(1):5-11

100 Wei ML. Hermansky-Pudlak syndrome: a disease of protein trafficking and organelle function. Pigment Cell Res 2006; 19(1):19-42

101 Badolato R, Prandini A, Caracciolo S, et al. Exome sequencing reveals a pallidin mutation in a Hermansky-Pudlak-like primary immunodeficiency syndrome. Blood 2012;119(13): 3185-3187

102 Blavignac J, Bunimov N, Rivard GE, Hayward CP. Quebec platelet disorder: update on pathogenesis, diagnosis, and treatment. Semin Thromb Hemost 2011;37(6):713-720

103 Hayward CP, Rivard GE. Quebec platelet disorder. Expert Rev Hematol 2011;4(2):137-141

104 Paterson AD, Rommens JM, Bharaj B, et al. Persons with Quebec platelet disorder have a tandem duplication of PLAU, the urokinase plasminogen activator gene. Blood 2010;115(6):1264-1266

105 Van Geet C, Izzi B, Labarque V, Freson K. Human platelet pathology related to defects in the G-protein signaling cascade. J Thromb Haemost 2009;7(Suppl 1):282-286

106 Gabbeta J, Vaidyula VR, Dhanasekaran DN, Rao AK. Human platelet Galphaq deficiency is associated with decreased Galphaq gene expression in platelets but not neutrophils. Thromb Haemost 2002;87(1):129-133

107 Freson K, Thys C, Wittevrongel C, et al. Pseudohypoparathyroidism type Ib with disturbed imprinting in the GNAS1 cluster and Gsalpha deficiency in platelets. Hum Mol Genet 2002;11(22): 2741-2750

108 Noé L, Di Michele M, Giets E, et al. Platelet Gs hypofunction and abnormal morphology resulting from a heterozygous RGS2 mutation. J Thromb Haemost 2010;8(7):1594-1603

109 Jurk K, Schulz AS, Kehrel BE, et al. Novel integrin-dependent platelet malfunction in siblings with leukocyte adhesion deficiency-III (LAD-III) caused by a point mutation in FERMT3. Thromb Haemost 2010;103(5):1053-1064

110 Hayward CP. Diagnostic evaluation of platelet function disorders Blood Rev 2011;25(4):169-173

111 Kuijpers TW, van de Vijver E, Weterman MA, et al. LAD-1/variant syndrome is caused by mutations in FERMT3. Blood 2009; 113(19):4740-4746

112 Defreyn G, Machin SJ, Carreras LO, Dauden MV, Chamone DA Vermylen J. Familial bleeding tendency with partial platelet thromboxane synthetase deficiency: reorientation of cyclic endoperoxide metabolism. Br J Haematol 1981;49(1):29-41

113 Di Paola J, Johnson J. Thrombocytopenias due to gray platelet syndrome or THC2 mutations. Semin Thromb Hemost 2011; 37(6):690-697

114 Lhermusier T, Chap H, Payrastre B. Platelet membrane phospholipid asymmetry: from the characterization of a scramblase activity to the identification of an essential protein mutated in Scott syndrome. J Thromb Haemost 2011;9(10):1883-1891 
115 Weiss HJ. Impaired platelet procoagulant mechanisms in patients with bleeding disorders. Semin Thromb Hemost 2009;35(2): 233-241

116 Albers CA, Paul DS, Schulze H, et al. Compound inheritance of a low-frequency regulatory SNP and a rare null mutation in exonjunction complex subunit RBM8A causes TAR syndrome. Nat Genet 2012;44(4):435-439, S1-S2

117 Huizing M, Parkes JM, Helip-Wooley A, White JG, Gahl WA. Platelet alpha granules in BLOC-2 and BLOC-3 subtypes of Hermansky-Pudlak syndrome. Platelets 2007;18(2):150-157

118 Thrasher AJ. New insights into the biology of Wiskott-Aldrich syndrome (WAS). Hematology (Am Soc Hematol Educ Program) 2009;1:132-138

119 Othman M. Platelet-type Von Willebrand disease: three decades in the life of a rare bleeding disorder. Blood Rev 2011;25(4): 147-153

120 Owen C. Insights into familial platelet disorder with propensity to myeloid malignancy (FPD/AML). Leuk Res 2010;34(2):141-142

121 Raslova H, Komura E, Le Couédic JP, et al. FLI1 monoallelic expression combined with its hemizygous loss underlies ParisTrousseau/Jacobsen thrombopenia. J Clin Invest 2004;114(1): 77-84

122 Favier R, Jondeau K, Boutard P, et al. Paris-Trousseau syndrome : clinical, hematological, molecular data of ten new cases. Thromb Haemost 2003;90(5):893-897

123 Noris P, Perrotta S, Seri M, et al. Mutations in ANKRD26 are responsible for a frequent form of inherited thrombocytopenia: analysis of 78 patients from 21 families. Blood 2011;117(24): 6673-6680

124 Mezzano D, Quiroga T, Pereira J. The level of laboratory testing required for diagnosis or exclusion of a platelet function disorder using platelet aggregation and secretion assays. Semin Thromb Hemost 2009;35(2):242-254

125 Quiroga T, Goycoolea M, Matus V, et al. Diagnosis of mild platelet function disorders. Reliability and usefulness of light transmission platelet aggregation and serotonin secretion assays. $\mathrm{Br} \mathrm{J}$ Haematol 2009;147(5):729-736
126 Hayward CP, Moffat KA, Liu Y. Laboratory investigations for bleeding disorders. Semin Thromb Hemost 2012;38(7): $742-752$

127 Gunay-Aygun M, Huizing M, Gahl WA. Molecular defects that affect platelet dense granules. Semin Thromb Hemost 2004; 30(5):537-547

128 Sandrock K, Zieger B. Current Strategies in Diagnosis of Inherited Storage Pool Defects. Transfus Med Hemother 2010;37(5): 248-258

129 Corral J, González-Conejero R, Pujol-Moix N, Domenech P, Vicente V. Mutation analysis of HPS1, the gene mutated in HermanskyPudlak syndrome, in patients with isolated platelet densegranule deficiency. Haematologica 2004;89(3):325-329

130 Cattaneo M, Lecchi A, Lombardi R, Gachet C, Zighetti ML. Platelets from a patient heterozygous for the defect of P2CYC receptors for ADP have a secretion defect despite normal thromboxane A2 production and normal granule stores: further evidence that some cases of platelet 'primary secretion defect' are heterozygous for a defect of P2CYC receptors. Arterioscler Thromb Vasc Biol 2000;20(11):E101-E106

131 Jagadeeswaran P. Zebrafish: a tool to study hemostasis and thrombosis. Curr Opin Hematol 2005;12(2):149-152

132 Dubé JN, Drouin J, Aminian M, Plant MH, Laneuville O. Characterization of a partial prostaglandin endoperoxide $\mathrm{H}$ synthase-1 deficiency in a patient with a bleeding disorder. $\mathrm{Br} J$ Haematol 2001;113(4):878-885

133 Isidor B, Dagoneau N, Huber C, et al. A gene responsible for Ghosal hemato-diaphyseal dysplasia maps to chromosome 7q33-34. Hum Genet 2007;121(2):269-273

134 Pham A, Wang J. Bernard-Soulier syndrome: an inherited platelet disorder. Arch Pathol Lab Med 2007;131(12):1834-1836

135 Toriello HV. Thrombocytopenia-absent radius syndrome. Semin Thromb Hemost 2011;37(6):707-712

136 Huizing M, Helip-Wooley A, Westbroek W, Gunay-Aygun M, Gahl WA. Disorders of lysosome-related organelle biogenesis: clinical and molecular genetics. Annu Rev Genomics Hum Genet 2008; 9:359-386 